\title{
COVID-19: incertidumbre de la anestesia
}

\author{
COVID-19: uncertainty of anaesthesia
}

Dra. Gloria María Alvarez-Bobadilla*

L a respuesta mundial de salud pública ante COVID-19 es masiva. Las instituciones de salud ـ están operando a su máxima capacidad, observamos cómo las organizaciones médicas se expanden hasta sus límites y los profesionales de la salud trabajan intensamente, incluso a sabiendas de que se exponen al riesgo de contraer el virus.

La pandemia por la propagación del nuevo coronavirus trae consigo desafíos en todos los niveles, desde la capacidad de respuesta del sistema de salud y el involucramiento social para acompañar las disposiciones, hasta el alcance de las estrategias para proteger a los más vulnerables y mitigar los efectos en la economía. De manera que, hoy más que nunca, necesitamos centrarnos en la cooperación multidisciplinaria sin fronteras, con apoyo de las autoridades y con la colaboración urgente de las áreas de la investigación, la academia y la comunidad clínica.

En estos momentos nuestro país ya vive en un estado de emergencia sanitaria por el incremento exponencial de contagios, por lo que las autoridades recomiendan, principalmente, no salir de casa, guardar la sana distancia entre las personas y la higiene. Mientras que, por otra parte, debemos afrontar y abordar la escasez de recursos humanos y materiales.

No se conoce si la pandemia desaparecerá totalmente después de alcanzar su máxima expansión, se quedará como una epidemia estacional o incluso como una enfermedad endémica. Si bien existe la idea de que, como sucede con la mayoría de los virus respiratorios, la transmisión y la enfermedad tenderá a desaparecer cuando se eleve la temperatura climática; sin embargo, no podemos garantizar que sucederá así.

Por otro lado, no se ha encontrado un tratamiento específico. Ciertamente se han corrido varios ensayos clínicos, todos ellos en fase de prueba, por lo que los resultados no son hasta ahora concluyentes y no se sabe si se producirán tratamientos efectivos antes de que remita la pandemia. Lo mismo puede decirse de la vacuna en la que obviamente se está trabajando mucho, pero que parece poco probable, aunque no imposible, que se desarrolle antes del verano.

Tampoco está clara cuál es la mejor estrategia para detener su transmisión, ya que se han ensayado dos modelos poblacionales: el aislamiento riguroso y la realización de pruebas generalizadas, estas últimas focalizándose en el aislamiento sobre los pacientes con resultados positivos y sus contactos. En todo caso es evidente que reducir los contactos de las personas infectadas y de todas las personas es una manera eficaz de cortar la cadena de transmisión; por lo que ambas estrategias son útiles y deben valorarse de acuerdo con la situación concreta de cada comunidad, sin duda cuanto antes se tome consciencia y se pongan en marcha, se logrará la contención. De cualquier modo, como el período de incubación es de alrededor de 14 días, cualquier actuación de este tipo no es de esperar que tenga un impacto razonable antes de este plazo.

Otra situación para subrayar es la competencia profesional y la condición psicológica del personal de salud. No es posible permanecer indiferente al medio, es normal que todo el equipo sanitario presente en algún momento confusión, inquietud, descontrol, miedo, culpa, impotencia, tristeza, irritabilidad, labilidad, entre otros. Son precisamente estas emociones las que nos hacen humanos; por lo cual, concebirlas como reacciones normales ante una situación anormal contribuye a su mejor manejo. No obstante, el malestar aqueja.

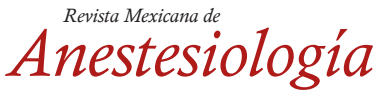

Abril-Junio 2020

Vol. 43. No. 2. pp 79-80

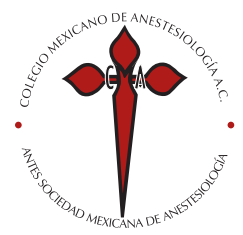

* Médica Anestesióloga del Hospital Central Sur de Alta Especialidad de Petróleos Mexicanos. Licenciada en Psicología. Subespecialista en Cuidados Paliativos. Maestría en Educación para la Salud, Maestría en Administración, Maestría en Tanatología. Presidenta del Colegio Mexicano de Anestesiología, A.C.

Solicitud de sobretiros: Colegio Mexicano de Anestesiología, A.C. Providencia 835, Col. Del Valle Alcaldía Benito Juárez, C.P. 03100 Tels.: 56691457, 56691659

E-mail: info@comexane.com 
Los médicos estamos en exposición continua a la cara más dramática de esta enfermedad: la muerte y el sufrimiento en condiciones desoladoras. Esto moviliza una importante carga emocional que a nivel cognitivo se traduce en una ideación obsesiva en la que se confunde lo posible con lo improbable. Es importante entonces no perder la esperanza y recordar que, a pesar de los obstáculos o las frustraciones, se está cumpliendo una gran misión: atender la salud de la población.

Sin duda, el año 2020 ha impuesto en primer plano el riesgo de esta pandemia en la que debemos planificar y prepararnos para la resiliencia como sociedad. Una respuesta colectiva y organizada es clave en vista de que las consecuencias futuras pueden ser decisivas. Debemos centrarnos en que a pesar de la incertidumbre y la resistencia al desconocido brote viral, habrá recuperación; deberíamos comenzar a evaluar y hacer un balance de las lecciones aprendidas. Lo que si bien es cierto es que las crisis mundiales persistirán y continuarán repitiéndose. Por esta razón debemos mirar al pasado y al presente para aprender y reconsiderar acciones para mejorar nuestras prácticas futuras.

Un punto por resaltar es que pertenecemos a una congregación de la que podemos sentirnos orgullosos: representamos un grupo de trabajadores del sistema sanitario que estamos dando la batalla día a día. Un ejemplo específico y un merecido reconocimiento para los «expertos de la vía aérea» que se han plantado en la primera línea para confrontar a los casos más graves, hay testimonio contundente del actuar de los anestesiólogos, quienes han dado muestra de su noble actuar ante la adversidad, la carencia y la conmiseración, incluso arriesgando su propia vida por sacar adelante la de otros.

A la par, es meritorio y digno de enfatizar el esfuerzo del personal sanitario, tal como los científicos que están en una carrera contra el tiempo para desarrollar terapias. Otro grupo importante de profesionales se encuentran dando difusión y educación médica continua especializada a través de los medios de comunicación para prevenir, tratar y paliar este padecimiento. $\mathrm{Al}$ igual que todo el personal que labora en nosocomios, médicos de otras especialidades, enfermería, ingenieros biomédicos, técnicos, personal de limpieza, camilleros y demás. Asimismo, diversos grupos de ciudadanos proactivos se han organizado para aportar soluciones a los desafíos que nos trae la pandemia, realizando donativos y respondiendo con ideas innovadoras y creativas para hacer frente a la precariedad y la deficiencia de insumos. Si bien es tiempo de incertidumbre, también es tiempo de solidaridad.

La adversidad forma parte de la vida e inevitablemente nos tropezaremos con ella. Cuando eso sucede, lo más importante no es la experiencia que vivimos, sino cómo la vivimos y lo que hacemos con ella. Bernice Johnston Reagon refiere: «los retos de la vida no están hechos para paralizarte, sino para ayudarte a descubrir quién eres». Nuestra vocación médica nos llevó un día a elegir nuestra profesión, dignifiquemos entonces nuestro proceder. Ánimo, estamos de pie. Colega, eres un héroe. 